\begin{tabular}{|lr|}
\hline Social Work/Maatskaplike Werk Vol 56 No 4 ; Issue 3 \\
http://socialwork.journals.ac.za/pub & doi:http://dx.doi.org/10.15270/56-4-882 \\
\hline
\end{tabular}

\title{
AFRICAN SPIRITUALITY: UNEARTHING BELIEFS AND PRACTICES FOR THE HELPING PROFESSIONS
}

Charlene Singh, Raisuyah Bhagwan

Empirical work related to African spirituality in the social sciences, particularly within the social work context, is sparse. It is crucial that practitioners have a deeper understanding of the beliefs and practices that can support therapeutic goals in practice. Using qualitative research methodology, 20 child and youth care students at a selected university in South Africa, who are proponents of African spirituality, were interviewed with regards to their beliefs and practices. The major objective was to gain a richer insight into African spirituality and those African healing methodologies considered most relevant to child and youth care practice. Prayer to the ancestral spirits, sacrificial rituals and music were considered to be some of the most important practices identified that could guide both child and youth care practice and social work.

Ms Charlene Singh, Department of Community Health Studies, Durban University of Technology, Durban, South Africa.

Prof Raisuyah Bhagwan, Department of Community Health Studies, Durban University of Technology, Durban, South Africa.

Charlene Singh, ORCID iD: 0000-0001-7859-5006

Raisuyah Bhagwan, ORCID iD: 0000-0002-1584-9432

singhc@dut.ac.za

bhagwanr@dut.ac.za

Keywords: African spirituality, beliefs, ceremonies, healing methodologies, helping professions, practices 


\title{
AFRICAN SPIRITUALITY: UNEARTHING BELIEFS AND PRACTICES FOR THE HELPING PROFESSIONS
}

\section{Charlene Singh, Raisuyah Bhagwan}

\author{
Ms Charlene Singh, Department of Community Health Studies, Durban University of Technology, \\ Durban, South Africa. \\ Prof Raisuyah Bhagwan, Department of Community Health Studies, Durban University of Technology, \\ Durban, South Africa.
}

\section{INTRODUCTION}

The need for a spiritually sensitive approach to social work practice has grown within the global landscape (Bullis, 2013; Crisp, 2016; Holloway \& Moss, 2010). Concomitant with this, the related literature on Christianity, Islam and Hinduism has grown in a quest to make practitioners take greater cognisance of the spiritual needs and practices of clients from these backgrounds (Bhagwan, 2017). This highlights the need for African spirituality also to be recognised alongside these other faith traditions, but more importantly for local practitioners to be able to tap into the therapeutic methods it offers within the context of practice. Whilst scholarly work related to Western traditions and approaches has received considerable attention, the literature on African spirituality in a local context has been sparse (Ross, 2010). Several scholars have, however, undertaken studies which document support for the inclusion of spirituality in social work (Bhagwan, 2010; Ross, 2010; Sacco, 1996). It is therefore time that greater attention be paid to the therapeutic richness offered by African spirituality, particularly the healing methodologies used by its adherents. It is against this background that the current study was undertaken to explore through a qualitative inquiry the healing methodologies and approaches that were most relevant to work with African youths, their families and communities.

\section{LITERATURE REVIEW}

\section{Religion and spirituality in social work practice}

The literature related to spirituality at the interface of child and youth care is sparse. There is, however, a significant amount of published work on spiritually sensitive social work which has a bearing on how both child and youth care practitioners as well as social workers may work more sensitively with matters of religion and spirituality with individuals, families and communities. This literature is reviewed below.

Academic interest in spirituality and religion has grown dramatically over the past few decades in the international context (Carlisle, 2016). It is increasingly recognized that these two constructs play important roles in the lives of many, if not all, clients (Holloway \& Moss, 2010). Consequently, social work, along with other helping professions, have incorporated these constructs into professional discourse (Hodge, 2018; Koenig, 2013;). Religion and spirituality are seen as multifaceted, overlapping constructs but a precise definition of spirituality is elusive in social work literature (Senreich, 2013). The definition offered by Puchalski, Ferrell, Virani, Otis-Green, Baird, Bull, Chochinov, Handzo, Nelson-Becker, Prince-Paul and Pugliese (2009: 887) reflects the view that spirituality is that part of humanity that refers to the way a person experiences their connectedness to self, to others, to nature, and to the significant or sacred. Religion has been defined as a "system of beliefs and practices observed by a community, supported by rituals that acknowledge, worship, communicate with, or approach the Sacred, the Divine, God ... or Ultimate Truth" (Koenig, 2008:11).On the other hand, spirituality has been conceptualised as a "personal quest for understanding answers to ultimate questions about life, about meaning, and about relationship to the sacred or transcendent, which may (or may not) lead to or arise from the development of religious rituals and formation of community"(Koenig, 2001:18). Although distinct, the two terms overlap (Hodge, 2015), especially with regards to "feelings, thoughts, experiences, and behaviours that arise from the search for the 
sacred" (Hill, Pargament, Wood, Mccullough, Swyers, Larson \& Zinnbauer, 2000: 66). For example Praglin's (2004:74) definition of religion is congruent with the traditional view, namely as a "culturally shared system of values, beliefs, and rituals which include spiritual concerns." Gardner (2016: 182), however, rightfully points out that, this search for the sacred encompasses both religious and spiritual expression, particularly for those clients who follow a particular faith tradition and to those who make connections across religious beliefs to form their own spiritual understanding. This paper is guided by this understanding.

Given that religion and spirituality are important dimensions of most clients' lives, its integration into practice may potentially improve health and mental health outcomes (Koenig, 2015; Koenig, King \& Carson, 2012; Koenig, McCullough, \& Larson, 2012). Research has highlighted the positive effects of spirituality and spiritually based activities on the health and wellbeing of people (Webb, Hirsch, Visser \& Brewer, 2013). Spirituality has proven to be effective in reducing stress and strengthening resilience, making it an important social work tool (Belcher \& Mellinger, 2016; Corry, While, Neenan \& Smith, 2014).

Spiritual traditions help people make sense of life-altering events (Johnstone, Yoon, Cohen, Schopp, McCormack, Campbell \& Smith, 2012). Moreover spirituality often helps people make sense of life issues and complements social work's holistic biopsychosocial model of practice (Belcher \& Mellinger 2016). In clinical practice social workers might request detailed information about religious and/or spiritual beliefs and practices during the assessment phase, or incorporate spiritual and religious interventions based on a client's spiritual background (Bhagwan, 2013). A comprehensive biopsychosocial assessment can explore the nature and depth of spiritual and religious beliefs and practices, as well as potential support systems for clients (Doka, 2011; Furman, Zahl, Benson, \& Canda, 2007). A thorough assessment will therefore allow the practitioner to treat the service recipient according to his or her needs (Crisp, 2008; Mulder, 2015).

A routine assessment of all incoming clients' religious or spiritual backgrounds will potentially help stimulate this discussion, which may offer useful information, clinically relevant strengths or struggles, and potential areas to tailor interventions that are often not explored. (Oxhandler \& Parrish, 2016). Canda and Furman (2010) reported that a majority of social workers considered various spiritually related helping interventions to be appropriate helping interventions, but few have personally used the intervention with clients. This may stem from a lack of educational preparedness to deal with these issues in practice (Bhagwan, 2010).

It is therefore crucial that social work educators expand their pedagogical toolbox to include teaching methods that integrate spirituality with practice, at a micro and a macro level (Belcher \& Mellinger 2016; Seitz, 2014). Studies suggest that most social workers receive minimal instruction on spirituality during their training (Canda \& Furman, 2010; Furness \& Gilligan, 2014; Oxhandler, Parrish, Torres \&Achenbaum, 2015). This is true of the South African context as well (Bhagwan, 2010). The lack of instructional content as part of undergraduate preparedness may help explain resistance in terms of incorporating matters of religion and spirituality in interactions with clients (Bhagwan, 2010; Bhagwan, 2013; Hodge 2018; Sheridan, 2009). Despite their lack of training, social workers are still obliged to attend to clients' spiritual lives in practice (Oxhandler \& Giardina 2017) as part of a holistic approach to social work.

Sheridan (2017:152) offer general guidelines for spiritually sensitive and competent practice that include: (a) learning about various religious/spiritual paths and their meaning for clients (particularly those whom social workers serve most frequently); (b) understanding the historical and current role of religion/spirituality in the oppression and liberation of marginalize groups; (c) engaging in ongoing self-reflection about one's own beliefs that includes examining one's biases; (d) attaining knowledge and skills to appropriately and effectively use spiritually-derived interventions; and (e) develop working relationships with community religious/spiritual leaders for consultation and collaboration (see also Kvarfordt \& Herba, 2018). These guidelines, particularly learning about diverse spiritual paths, 
grounds this paper in terms of understanding traditional African spiritual beliefs, particularly how their healing methodologies can guide practice. Moreover, the last two guidelines are important within the context of the current paper, which focuses on using traditional spiritual interventions to support social work intervention in the African community.

\section{Afrocentric social work}

Thabede (2008:234), who advocated Afrocentric social work, emphasised the need for social workers to understand the importance of rituals, traditional healing and ancestral worship when working with African clients. He wrote that the Afrocentric perspective requires that helping professionals, particularly those in the social sciences, create the space for ideas based on African culture about clinical intervention and to acknowledge that "African cultural knowledge is important in addressing the psychological, intellectual, spiritual and emotional needs of African people". Schiele (1996) conceptualised Afrocentric social work as an approach to practice which is predicated on traditional African philosophy that may be distilled to understand and solve individual and societal problems. An Afrocentric approach is connected with social work values which rest on a strengths-based approach and which operates within a holistic paradigm that recognises not only the indivisibility of the physical, psychological and spiritual realms of a person, but also the inseparability of the individual from the other systems, particularly family and community, within which an individual's care is nestled.

Adofo (2016) wrote that there are six components that underpin African spirituality, viz. the nature of existence; order and balance; the interconnectedness of things; social and spiritual hierarchy; cyclical existence; and the Spirit of Being. African spirituality is premised on the notion that all things have "the quintessential essence (Spirit) of the Creator" within them, be they animate or inanimate in nature. Hence it is believed that the human body and the rest of Creation hold the spirit and consciousness of the Creator (Marumo \& Chakale, 2018: 11698). Adofo (2016) contended that the ultimate intent for people to reunite their individualised consciousness with this Spirit can be achieved through living a righteous life that bestows the status of an ancestor upon death.

In the absence of formal religious texts, African spirituality has been passed down through the oral repository of African stories and songs from which people have distilled their spirituality and their healing methodologies for wellbeing (Thabede, 2008). African spirituality is thus predicated on the "bases of cyclical existence" (Marumo \& Chakale, 2018: 11698), not contained in a written text, but rather the African spiritual worldview honours the centrality of spirituality within all of life (Bhagwan, 2017). According to Adofo (2016), there are two aspects of the created universe: the physical and the spiritual. He wrote that the spiritual realm reflects various "spaces or abodes; those of departed ancestors, spirits (deities) and that of the penultimate source of Creation of all things." He added that both realms are in reciprocal contact with each other and hence what occurs within one realm impacts on and influences the other. Moreover, within the African worldview "humanity is in a relationship with environment, culture and tradition" (Marumo \& Chakale, 2018: 11700). In this vein Masango (2006) affirmed that African spirituality reflects the totality of life, it is non-dualistic and does not set up a dichotomy between the secular and the sacred, which grounds the need to include spirituality within the development of a therapeutic plan.

\section{METHODOLOGY}

A qualitative research paradigm was adopted for this study, as it aimed to explore what spiritual beliefs and practices were important when working with individuals and families from an African background. The participants included final-year child and youth care students from a University of Technology. These participants were selected because of their African background and ability to shed light on African spirituality and its healing methodologies. The intent then was to distil an understanding of African spirituality from their participation. Although it reflected their own beliefs and practises, it could be used to inform both child and youth care and social work practice with clients from an African background. 
Non-probability sampling, specifically purposive sampling, was used to recruit these participants. In total 20 students were interviewed using semi-structured interviews. There were 5 males and 15 females who were part of the sample; they had grown up within a family that adopted African Traditional Religion and African spiritual practices. The primary objective was to understand the spiritual beliefs and practices and the healing methodologies used within the context of African spirituality. The process of data analysis was guided by thematic analysis. It involved identifying and analysing patterns presented in qualitative data from which themes were derived (Braun \& Clark 2006). Through this rigorous process of thematic analysis, seven themes emerged. They are presented in the sub-sections that follow.

\section{ANALYSIS AND DISCUSSION}

Seven broad themes emerged.

\section{Theme 1: Prayer to the Unseen Spirit}

Most participants indicated the importance of prayer as an important spiritual practice for healing. They said:

Prayer is very important for healing. (P 7)

It is a way to seek comfort in the Unseen. (P 3)

I have a strong belief in the Unseen. You can't see it but you know it will guide you. (P 8)

Prayer to a Spirit that influences you and drives you. God is a Spirit and ancestors are also spirits ... this Spirit is very important. (P 9)

As evident in the comments above, prayer to an unseen spirit emerged as one of the key features of African spirituality. Tapping into a source of Divinity, which is easily accessible (Sion \& Nash, 2013) or closeness to God during prayer, has been known to provide a deep sense of strength and courage to overcome adversities (Moore, Talwar \& Bosacki, 2012). As reflected in the comments, prayer to the Unseen Spirit or the ancestors were regarded as an important spiritual practice that can support individuals and families going through a crisis. As such it can be applied as a spiritually based activity when child and youth care practitioners or social workers encounter individuals in distress.

God within the context of African spirituality is seen as "The Great Spirit, The Creator and Sustainer of the Universe" and "the Very Source of Being" (Nkulu-N'Sengha, 2009: 290). The most salient attribute of this "Unseen Spirit," is the notion that this "Unseen Spirit," can bring justice to earth and uphold morality and social order. According to Ntseane (2011), all of humankind is connected to this Divine Being who can be approached through prayers, sacrificial offerings, singing and dancing, rituals and human and spiritual intermediaries (Cook \& Wiley, 2000). The importance of ancestral worship also emerged as unequivocally linked to the Supreme God in African spirituality (Bhagwan, 2017). Spirituality can offer a sense of hope in the context of the hopelessness of trauma. Finding some sense of meaning, of belief in a power outside of one's self can contribute to a sense of hopefulness (Perez, Moreira-Almeida, Naello \& Koenig, 2007). The positive spiritual coping resources described draw upon the power of God to address this sense of hopelessness. Spirituality in the form of various religious traditions also offers a sense of power in partnership ("God on my side") with the divine and growth in personal strength to counter the sense of helplessness, vulnerability, and powerlessness (Perez, et al, 2007; Mhum, et al, 2011; Hrostolwski \& Rehner, 2012). This is evidenced in the comments under theme 2 .

\section{Theme 2: Prayer to ancestral Spirits}

Participants said:

Ancestors are spirits that influence you ... God is a Spirit and ancestors are also Spirits ... this Spirit is very important too. God guides you and helps you to make right decisions. (P 16) 
Communicating with the ancestors helps ...(P 6)

It is a passage to God ... when I pray to the ancestors. (P 12)

Ancestors guide you and if you are spiritual, you believe in them. When you believe in them, you feel comfort. (P 13)

My grandparents believed in the ancestors and I've seen them feel peaceful after communicating with the ancestors. It helps people feel spiritual. (P 11)

Spirituality in the African paradigm is connected to a sense of respect for the departed, who ultimately guides an individual to God and who always listens (Edwards, 2013, Moore, Talwar \& Bosacki, 2012; Wintersgill, 2008). Most of the participants viewed the ancestors as having the same Divine power as the Supreme God. According to Mbiti (1990), ancestors live within the spirit world and act as conduits between their families and the sphere of divinity. They are seen as providers of safety and are called upon during times of calamity (Marumo \& Chakale, 2018:11695). Moreover, their guidance and blessings are often received when the relevant rituals are conducted and sacrificial offerings are made (Thabede, 2008: 239). Whilst they offer guidance, protection and blessings, they may also mete out punishment if family rituals are not observed (Ross, 2018:11). Thabede (2008: 239) therefore argued that failure to show them proper respect, invites misfortunes, hence veneration ensures blessings and protection. Hence this deep connection to the ancestors with "dreams and visions seen as coming from the ancestral realm" remains one of the most salient spiritual pathways for receiving messages that influence health and wellbeing" (Ohajunwa \& Mji, 2018:2524).

The emphasis placed on prayers and offerings to the ancestors reflects their importance to people in crisis in two ways. It is possible that clients may attribute their difficulties to the fact that they did not show respect towards the ancestors, or they may believe that through prayers and offerings to the ancestors their problems would be resolved.

\section{Theme 3: Sacrificial rituals}

Participants also expressed the view that that sacrificial rituals were important spiritual practices that allow help to be summoned from the ancestors in overcoming bad luck or bad experiences. Johnson (2015:278) said that "Zulus believe that there is no such thing as chance and that misfortunes are believed to be due to some external agency that brought it on." This suggests that the ancestral spirits have to be appeased through rituals during times of crisis. The comments below capture these sentiments:

People slaughter to ward off bad luck. Slaughtering of cows is done to ask for forgiveness as well. (P 7)

Seeking help from the ancestors for healing means engaging in sacrificial prayer. (P 11)

Thabede (2008) wrote that help and guidance are sought from ancestors through sacrificial rituals and offerings. Sacrificial prayer within the context of African spirituality entails the slaughtering of goats and cows and serves as a medium of communicating with the ancestors during the offering (Govender \& Ruggunan 2013; Mnguni 2006). Hutchings (2007) added that this type of ritual, which may involve washing the individual with the blood of the animals sacrificed, is a practice of cleansing that is believed to heal a person and rid the individual of the bad luck or relieve them of a traumatic experience. This is explained further in the theme 4 .

\section{Theme 4: Cleansing rituals}

Spirituality can be accessed through rituals or practices that help provide meaning and support (Hrostolwski \& Rehner, 2012; Van Hook, 2016). Cleansing rituals are another type of spiritual practice that emerged in the data. Participants indicated that these are often performed by a traditional healer and that this practice is often carried out after a person has been 'bewitched' or after the traumatic death of a family member. They said: 
Cleansing ceremonies are very important in the Zulu culture. (P 7)

Well I know that they use cleansing methods when someone is bewitched. (P 3)

People do cleansing prayer like if someone sinned and wants to repent or someone is troubled by a spirit then they would be cleansed to heal from it. (P 4)

Burning of wood and ash and then added to water for cleansing. This makes people feel like they have got rid of their problems. (P 14)

Cleansing ceremonies are done for people. People also call isangomas to cleanse the house. In rural communities there is a belief that black magic is common. (P 18)

Cleansing rituals therefore also form an important traditional healing method in African spirituality that are believed to restore harmony and balance in an individual (Agyekum \& Newbold 2016; Bhikha \& Glynn, 2013). Vinesett, Price and Wilson (2015) supported this notion saying that they are particularly significant when individuals experience stress, as they can transform an individual from their traumatic state into a state of enhanced wellbeing. They are in fact intended to assist an individual to acknowledge their pain and through spiritual connectedness with unseen Spirit, transcend these difficulties and move forward (Stark, 2006). Through the use of herbal medication and spiritual support, the cleansing ritual is believed to effect wellbeing. Cleansing rituals also make use of water, plants, smoke/fire and mud to effect healing.

Daniels (2016: 21) reported that cleansing rituals are significant to "rid one's body of diseases, protect children from harm, sanctify a public place, and repair broken relationships." It is believed that if a person is not cleansed, misfortune will follow and this will affect not just the individual but also an entire community (Awolalu, 1976). Hence, Nolte-Schamm (2006) argued that cleansing rituals are also important for the restoration and healing of families and communities as well. An entire tribe may therefore come together or an entire lineage for rituals when challenges are experienced (Ohajunwa \& Mji, 2018).

Thabede (2008:241) asserted that it was important that social workers acknowledge the importance of cleansing rituals when clients are faced with difficulties. These cleansing rituals can be achieved through various spiritual rites that are believed to facilitate connectedness to God and ancestors, self and others, the earth, plants and animal life (Ohajunwa \& Mji, 2018:2525). Another important aspect that emerged in the data was that an African client's belief in witchcraft means that they may attribute their difficulties to the fact that someone is bewitching them. Thabede (2008) added that within the African community death, divorce, accidents and other psychological difficulties are often linked to witchcraft and clients must feel comfortable enough to share their beliefs with practitioners, who may often not see this as rational. Hence, when they wish to incorporate these rituals as part of healing, they should be supported.

\section{Theme 5: Music}

Drumming was also viewed as an important spiritually based practice in African spirituality. Participants felt that drumming and singing were a way of getting in touch with a Higher Spirit or their ancestors. Moreover participants felt that drumming had individual therapeutic benefits. The excerpts below reflect these views:

\section{African drumming keep individuals rooted and connected to a Higher Spirit. (P11)}

Drumming is very soothing. When you drum you feel that you are letting out your aggression and when you listen to drum beats you feel energised. (P 5)

Praying together, singing together and even doing creative activities together is spirituality. When we are able to be among others and have positive interactions we feel spiritual. (P 20)

Dancing helps to get rid of hurt and pain and allows the person to express their emotions. (P 8) 
People from the family also go to gatherings held by families during rituals and sing and dance with them. And this brings families together and people feel happier. (P 20)

Drumming is a common practice in the African tradition which enhances the way in which individuals and communities call on their ancestors. People are believed to experience a sense of calmness and guidance, as they feel the presence and closeness of the ancestors when they drum. In addition, it fosters a spirit of togetherness with community members and family. Apart from getting in touch with ancestral Spirits through drumming, group drumming is beneficial in reducing depression and anxiety (Wood, Ivery, Donovan \& Lambin, 2013; Fancourt, Perkins, Asenso, Carvalho, Steptoe \& Williamon, 2016). In Zulu culture dancing is a common practice and facilitates expression of feelings. Since such practices are culturally familiar to individuals, it allows for experiences of comfort and contentment when practised. Singing, dancing and drumming are also important method that can support clients during a crisis.

\section{Theme 6: Consultation with traditional healers}

Participants also recognised that traditional healers also play an important role in African spirituality. They said:

Sometimes when people have problems they call the Inyanga to their homes late at night where the Inyanga will pray whole night and make medicines for them to take. But no one else must see it so the Inyanga goes very early before people get up. (P 8)

Community turn to isangomas (traditional healer) for help. Zulu people believe that isangoma can solve problems, like if you feeling sick or have body pains or you are worried about something. Especially when people have bad luck, they visit the isangoma. (P 15)

Healing in African culture is an inextricable component of African spirituality and traditional way of living. According to participants, African people are deeply rooted in their spiritual beliefs and methods of traditional healing and therefore have an unwavering faith in healing through a traditional healer. Family and community members seek help from traditional healers who give home-grown medication such as herbs or ointments to calm a person and relieve a person who is experiencing physical or emotional pain. The use of animal bones, indigenous herbs and their elevated spiritual status has earned traditional healers' great reverence and they are seen as equivalent to the Supreme Being (Essien, 2013). Hence, when faced with trauma, anxiety and depression, individuals and families turn first to traditional healers for help to transcend their difficulties.

Washington (2010:26) described a traditional healer as a "person of great respect in the community", who can be trusted by community members in times of adversity. Traditional healers are believed to be powerful individuals who serve the community through the use of indigenous knowledge, to heal the ailments of the individuals, communities and families (Essien, 2013; King, 2012). These traditional healers receive a spiritual calling to serve the people (Holland, 2012). Furthermore, the traditional healer is respected for helping individuals overcome several problems such as bad luck, restoring relationships, psychological problems and not just physical ailments (Sodi \& Bojuwoye, 2011).

It is for these reasons that African people turn to traditional healers during times of need as they diagnose illness, identify problems and find solutions through communication with the ancestors (Jithoo \& Bakker, 2011). Ross (2018:6) noted that there are approximately 25000 and 400000 traditional healers in South Africa and, because they are more geographically accessible and they understand the social cultural, economic and political context of their patients, it is believed that eighty percent of the black population are reliant on them; respectful and support for traditional healers is crucial as they have an overall therapeutic plan.

\section{Theme 7: Community connectedness and the role of elders}

Participants also emphasised the importance of community and the role of elders as important aspects of African spirituality: 
When there is a death in the family then all community members and neighbours go to the house straight away and offer support. (P 6)

Elders in the community help to mediate when there is conflict between people. They try to bring people together. Usually the Chief of the community holds a forum to listen to people's problems and then do something about it. (P 12)

Community members also try to help if there is a problem, like if someone from your family stole something from another family, then they will try to discipline the person or reunite families. (P 11)

Elders play an important role when people are confronted with distress. Several participants revealed that many families receive help from elders in the family or the community Head or Chief in times of grief or difficult family situations. Kovac (2012:13) confirmed such findings made, saying that those who follow the tenets of African spirituality often seek assistance from elders or local chiefs as "harmony in the community is practically equated with the respect for elders and local chiefs." Kovac (2012:13) added that, "every effort of community reconciliation or restoration of harmony has to involve the appreciation of the elders and the local chiefs."

As evident in the data above, participants reached out to family or other community elders when confronted with difficulties. People and families who benefit from the support of kinship networks feel a sense of connectedness, belonging, comfort and enhanced holistic wellbeing. Thabede (2008:238) also wrote that African people live by the basic principle of "collective identity as opposed to individual identity." Similar to the beliefs of many of the participants, this also confirms that the philosophy of kinship is used as a basic means of survival for Africans (Wheeler, Ampadu \& Wangari, 2002). Hence, elders have a crucial voice when it comes to negotiating and preventing violence in families and communities.

Moreover, participants reported that caring for others within the community is reflected as ubuntu within African spirituality. The literature has shown that the spirit of ubuntu is an African philosophy and the essence of African spirituality (Okoro, 2015). The term ubuntu reflects the notion that "my humanity is caught up and is inextricably bound with others. The spirit of Ubuntu can be described as an omnipresent spirit of caring [about] the humanity of others." (Ohajunwa \& Mji, 2018:2527). Hence the individual exists with, through and because of the collective. The collective also exists through and with the individual; the individual is strengthened, with the final outcome being the strengthening the collective (Mji, 2012).

The strong sense of community is aligned with Masango's (2006:113) views that “African people have no private faith or private spirituality," and that "the individual identity of an African almost does not exist" (Theletsane, 2012:271). Hence, extended family and community are crucial spiritual support systems that can be tapped into when clients face adversity.

The literature has also documented that family ties are significant to African people (Bell-Tolliver \& Wilkerson, 2011). Hence, kinship networks, the extended family, are believed to be the primary source of strength in African families during times of need. The extended family is responsible not only for providing material support, but also psychological support, and is usually guided by the oldest relative (Tshabalala, 1992).

Within African spirituality the notion of a "shared space," is central, because "the spiritual permeates the very flow of community and is embedded in structures, practices and the daily life of each member of the community." Hence when spirituality is considered within an African context, it is understood "as a collective spirituality" (Ohajunwa \& Mji, 2018:2524). Collective spirituality is seen as a connection to self and other people, to nature and to a higher being (Amanze, 2011). The individual self is therefore nestled firmly within the collective, because individual spirituality within an African context is practised in a way that ensures the wellbeing of the entire community (Mji, 2012). The role 
of elders and using the community as a support system are important considerations in both child and care practice and social work.

\section{CONCLUSION}

A deeper understanding of the African spiritual worldview and the healing method it embraces are crucial to informing practice within the helping professions. This paper revealed the beliefs and practices related to this traditional worldview in an attempt to enable practitioners to gain a deeper insight into the beliefs and practices embedded within the African spiritual worldview. A biopsychosocial and spiritual assessment is crucial to exploring the spiritual strengths embraced by adherents of African spirituality. Most importantly it should honour the healing methodologies that came to light within the context of this study, namely drumming, prayer and rituals. Moreover the salience of traditional healers in the lives of clients must be acknowledged and the rituals and treatment interventions developed by them respected within an overall helping plan that helping professionals such as social workers and child and youth care workers can embrace. Community support systems can also be tapped into to offer support to distressed or troubled families, given the emphasis that African spirituality places on the collective.

\section{REFERENCES}

ADOFO, D.K.Y. 2016. Ancestral voices: Spirit is eternal. United Kingdom: Dalian Y Adofo.

AGYEKUM, B. and NEWBOLD, B.K. 2016. Religion/spirituality, therapeutic landscape and immigrant mental well-being amongst African immigrants to Canada. Mental Health, Religion and Culture, 19(7):674-685.

AMANZE, J.N., 2011. Contextuality: African spirituality as a catalyst for spiritual formation in theological education in Africa. Ogbomoso Journal of Theology,16(2):1-23.

AWOLALU, J. O. 1976. What is African traditional religion? Studies in Comparative Religion, 10(2):1-10.

BELCHER, J.R. \& MELLINGER, M. 2016. Integrating spirituality with practice and social justice: The challenge for social work. Journal of Religion \& Spirituality in Social Work: Social Thought, 35(4):377-394.

BELL-TOLLIVER, L. \& WILKERSON, P. 2011. The use of spirituality and kinship as contributors to successful therapy outcomes with African American families. Journal of Religion and Spirituality in Social Work: Social Thought, 30(1):48-70.

BHAGWAN, R. 2010. Spirituality in social work: A survey of students at South African universities. Social Work Education, 29(2):188-204.

BHAGWAN, R. 2013. Spirituality in social work in South Africa: Insights from a survey with academics. International Social Work, 56(3):276-289.

BHAGWAN, R. 2017. The sacred in traditional African spirituality: creating synergies with social work practice. In: CRISP, B. R. (ed). The Routledge Handbook of religion, spirituality and social work. New York, NY: Routledge: 64-72.

BHIKHA, R. A. \& GLYNN, J. 2013. African traditional healing and Tibb. South Africa: Tibb.

BRAUN, V. \& CLARKE, V. 2006. Using thematic analysis in psychology. Qualitative Research in Psychology, 3(2):77-101.

BULLIS, R.K. 2013. Spirituality in social work practice. New York, NY: Taylor and Francis.

CANDA, E. R. \& FURMAN, L. D. 2010. Spiritual diversity in social work practice: The heart of helping. New York: Oxford University Press. 
CARLISLE, P. 2016. Religion and spirituality as troublesome knowledge: The views and experiences of mental health social workers in Northern Ireland. The British Journal of Social Work, 46(3):583598.

COOK, D.A. \& WILEY, C.Y. 2000. Psychotherapy with members of African American Churches and spiritual traditions. In: RICHARDS, P. S and BERGIN, A. E. (eds). Handbook of psychotherapy and religious diversity. Washington, DC: American Psychological Association: 369-396.

CORRY, M., WHILE, A., NEENAN, K. \& SMITH, V. 2015. A systematic review of systematic reviews on interventions for caregivers of people with chronic conditions. Journal of advanced nursing, 71(4):718-734.

CRISP, B.R., 2008. Social work and spirituality in a secular society. Journal of Social Work, 8(4): 363-375.

CRISP, B.R., 2016. Spirituality and social work. New York: Routledge.

DANIELS, K. M. 2016. The coolness of cleansing: Sacred waters, medicinal plants and ritual baths of Haiti and Peru. ReVista (Cambridge),16(1):21.

DOKA, K.J., 2011. Religion and spirituality: Assessment and intervention. Journal of Social Work in End-of-Life \& Palliative Care, 7(1):99-109.

EDWARDS, S. D. 2013. Intuition as a healing modality: Historical and contemporary perspectives. Journal of Psychology in Africa, 23(4):669-673.

ESSIEN, E. D. 2013. Notions of healing and transcendence in the trajectory of African traditional religion: Paradigm and strategies. International Review of Mission, 102(2):236-248.

FANCOURT, D., PERKINS, R., ASCENSO, S., CARVALHO, L. A., STEPTOE, A. \& WILLIAMON, A. 2016. Effects of group drumming interventions on anxiety, depression, social resilience and inflammatory immune response among mental health service users. PloS one, 11(3): e0151136.

FURMAN, L.D., ZAHL, M.A., BENSON, P.W. \& CANDA, E.R., 2007. An international analysis of the role of religion and spirituality in social work practice. Families in Society, 88(2):241-254.

FURNESS, S. \& GILLIGAN, P. 2014. 'It never came up': Encouragements and discouragements to addressing religion and belief in professional practice-what do social work students have to say? British Journal of Social Work, 44(3):763-781.

GARDNER, F., 2016. Critical Spirituality in Holistic Practice. Journal for the Study of Spirituality, 6(2):180-193.

GOVENDER, P. \& RUGGUNAN, S. 2013. An exploratory study into African drumming as an intervention in diversity training. International Review of the Aesthetics and Sociology of Music: 149-168.

HILl, P. C., PARGAMENT, K. I., WOOD, R. W., MCCUllough, M. E., SWYERS, J. P., LARSON, D. B. 7 ZINNBAUER, B. J. 2000. Conceptualizing religion and spirituality: Points of commonality, points of departure. Journal for the Theory of Social Behaviour, 30:51-77.

HODGE, D.R. 2015. Spirituality and religion among the general public: Implications for social work discourse. Social Work, 60(3):219-227.

HODGE, D.R. 2018. The evolution of spirituality and religion in international social work discourse: Strengths and limitations of the contemporary understanding. Journal of Religion \& Spirituality in Social Work: Social Thought, 37(1):3-23.

HOLLAND, H. 2012. African magic. UK: Penguin. 
HOLLOWAY, M. and MOSS, B., 2010. Spirituality and social work. Macmillan International Higher Education.

HROSTOLWSKI, S. and REHNER, T. 2012. Five years later: Resiliency among older adult survivors of Hurricane Katrina. Journal of Gerontological Social Work, 55(4):337-351.

HUTCHINGS, A. 2007. Ritual cleansing, incense and the tree of life-observations on some indigenous plant usage in traditional Zulu and Xhosa purification and burial rites. Alternation, 14(2): 189-217.

JITHOO, V. \& BAKKER, T. 2011. Family therapy within the African Context. Counselling People of African Ancestry, 142-154.

JOHNSON, M.P. 2015. African Dreamers and Healers. Psychological Perspectives, 58(3):265-308.

JOHNSTONE, B., YOON, D.P., COHEN, D., SCHOPP, L.H., MCCORMACK, G., CAMPBELL, J. \& SMITH, M. 2012. Relationships among spirituality, religious practices, personality factors, and health for five different faith traditions. Journal of Religion and Health, 51(4):1017-1041.

KING, B. 2012. We pray at the church in the day and visit the sangomas at night: Health discourses and traditional medicine in rural South Africa. Annals of the Association of American Geographers, 102(5):1173-1181.

KOENIG, H. G., KING, D. E. \& CARSON, V. B. 2012. Handbook of religion and health. New York: Oxford University Press.

KOENIG, H. G., MCCULlOUGH, M. E. \& LARSON, D. B. 2012. Handbook of religion and health. New York: Oxford University Press.

KOENIG, H.G. 2015. Religion, spirituality, and health: A review and update. Advances in Mind-body Medicine, 29(3):19-26.

KOENIG, H.G., 2013. Spirituality in patient care: Why, how, when, and what. Templeton Foundation Press.

KOENIG, H.G. 2008. Concerns about measuring "spirituality" in research. The Journal of Nervous and Mental Disease, 196(5):349-355.

KOENIG, H.G. 2001. Religion, spirituality, and medicine: How are they related and what does it mean? Mayo Clinic Proceedings, 76 (12):1189-1191).

KOVAC, U. 2012. The Savage bonfire: Practising community reconciliation in post conflict Sierra Leone. Utrecht: Utrecht University. (M thesis)

KVARFORDT, C.L. \& HERBA, K. 2018. Religion and spirituality in social work practice with children and adolescents: A survey of Canadian practitioners. Child and Adolescent Social Work Journal, 35(2):153-167.

MARUMO, P.O. \& CHAKALE, M.V. 2018. Understanding African philosophy and African spirituality: Challenges and prospects. Gender and Behaviour, 16(2):11695-11704.

MASANGO, M.J. 2006. African spirituality that shapes the concept of Ubuntu. Verbum et Ecclesia, 27(3):930-943.

MBITI, J.S. 1990. African religions and philosophy. Heinemann.

MHUM, T., BELL, H., PYLES, L. \& RUNNELS, R. 2011. Five years later: Resiliency among older adult survivors of Hurricane Katrina. Religion and Spirituality in Social Work: Social Thought. 30(3):294-311.

MJII, G. 2012. The health knowledge utilized by rural older Xhosa women in the management of health problems in their home situation, with a special focus on indigenous knowledge. Stellenbosch: Stellenbosch University. (Doctoral thesis) 
MNGUNI, M. E. 2006. An investigation into the commercial and the Zulu traditional modes of slaughtering, butchering, culinary properties and service with special reference to socio-cultural ritual behaviours in KwaZulu-Natal. Durban: Durban University of Technology. (M thesis)

MOORE, K., TALWAR, V. \& BOSACKI, S. 2012. Canadian children's perceptions of spirituality: Diverse voices. International Journal of Children's Spirituality, 17(3):217-234.

MULDER, C. 2015. From the inside out: Social workers' expectations for integrating religion and spirituality in practice. Journal of Religion \& Spirituality in Social Work: Social Thought, 34(2): 177-204.

NKULU-N'SENGHA, M. 2009. Luba. African Arts, 42(3):90-92.

NOLTE-SCHAMM, C. 2006. The African traditional ritual of cleansing the chest of grudges as a ritual of reconciliation. Religion and Theology, 13(1):90-106.

NTSEANE, P.G. 2011. Culturally sensitive transformational learning: Incorporating the Afrocentric paradigm and African feminism. Adult education quarterly, 61(4):307-323.

OHAJUNWA, C. \& MJI, G. 2018. The African Indigenous lens of understanding Spirituality: Reflection on key emerging concepts from a reviewed literature. Journal of Religion and Health, 57(6):2523-2537.

OKORO, N. K. 2015. Ubuntu ideality: The foundation of African compassionate and humane living. Journal of Scientific Research and Reports, 8(1):1-9.

OXHANDLER, H. K., PARRISH, D. E., TORRES, L. R. \& ACHENBAUM, W. A. 2015. The integration of clients' religion and spirituality in social work practice: A national survey. Social Work, 60:228-237.

OXHANDLER, H.K. \& GIARDINA, T.D. 2017. Social workers' perceived barriers to and sources of support for integrating clients' religion and spirituality in practice. Social Work, 62(4):323-332.

OXHANDLER, H.K. \& PARRISH, D.E. 2016. The development and validation of the religious/spiritually integrated practice assessment scale. Research on Social Work Practice, 26(3): 295-307.

PEREZ, J., MOREIRA-ALMEIDA, A., NAELLO, A. \& KOENIG, H. 2007. Spirituality and resilience in trauma victims. Journal of Religion Health, 46 (3):343-350.

PRAGLIN, L.J. 2004. Spirituality, religion, and social work: An effort towards interdisciplinary conversation. Journal of Religion \& Spirituality in Social Work: Social Thought, 23(4):67-84.

PUCHALSKI, C., FERRELL, B., VIRANI, R., OTIS-GREEN, S., BAIRD, P., BULL, J., CHOCHINOV, H., HANDZO, G., NELSON-BECKER, H., PRINCE-PAUL, M. \& PUGLIESE, K. 2009. Improving the quality of spiritual care as a dimension of palliative care: the report of the Consensus Conference. Journal of Palliative Medicine, 12(10):885-904.

ROSS, E. 2010. Inaugural lecture: African spirituality, ethics and traditional healing-implications for indigenous South African social work education and practice. South African Journal of Bioethics and Law, 3(1):44-51.

ROSS, E. 2018. Reimagining the South African social work curriculum: Aligning African and western cosmologies. Southern African Journal of Social Work and Social Development, 30(1):1-16.

SACCO, T. 1996. Spirituality and social work students in their first year of study at a South African university. Journal of Social Development in Africa, 11:43-56.

SCHIELE, J.H. 1996. Afrocentricity: An emerging paradigm in social work practice. Social Work, 41(3):284-294. 
SEITZ, C.R., 2014. Utilizing a spiritual disciplines framework for faith integration in social work: A competency-based model. Social Work and Christianity, 41(4):334.

SENREICH, E. 2013. An inclusive definition of spirituality for social work education and practice. Journal of Social Work Education, 49(4):548-563.

SHERIDAN, M. 2009. Ethical issues in the use of spiritually based interventions in social work practice: What are we doing and why. Journal of Religion \& Spirituality in Social Work: Social Thought, 28:99-126.

SHERIDAN, M.J. 2017. Learning with the labyrinth: Creating reflective space in Higher Education, by J. Sellers and B. Moss. Journal of Religion \& Spirituality in Social Work: Social Thought, 36(4): $479-480$

SION, T. \& NASH, P. 2013. Coping through prayer: An empirical study in implicit religion concerning prayers for children in hospital. Mental Health, Religion and Culture, 16(9): 936-952.

SODI, T. \& BOJUWOYE, O. 2011. Cultural embeddedness of health, illness and healing: Prospects for integrating indigenous and western healing practices. Journal of Psychology in Africa, 21 (3): 349356.

STARK, L. 2006. Cleansing the wounds of war: An examination of traditional healing, psychosocial health and reintegration in Sierra Leone. Intervention, 4 (3):206-218.

THABEDE, D. 2008. The African worldview as the basis of practice in the helping professions. Social Work/Maatskaplike Werk, 44(3):233-245.

THELETSANE, K.I. 2012. Ubuntu management approach and service delivery. The Journal of Public Administration, 47(1):265-278.

TSHABALALA, M. 1992. Multicultural social work practice: Alternative options for social work practice in South Africa. Journal of Multicultural Social Work, 2(2):65-80.

VAN HOOK, M.P. 2016. Spirituality as a potential resource for coping with trauma. Social Work and Christianity, 43(1):7.

VINESETT, A.L., PRICE, M. \& WILSON, K.H. 2015. Therapeutic potential of a drum and dance ceremony based on the African Ngoma tradition. The Journal of Alternative and Complementary Medicine, 21(8):460-465.

WASHINGTON, K. 2010. Zulu traditional healing, African worldview and the practice of Ubuntu: Deep thought for African/Black psychology. The Journal of Pan African Studies, 3(8):24-39.

WEBB, J.R., HIRSCH, J.K., VISSER, P.L. \& BREWER, K.G. 2013. Forgiveness and health: Assessing the mediating effect of health behavior, social support, and interpersonal functioning. The Journal of Psychology, 147(5):391-414.

WHEELER, E. A., AMPADU, L. M. \& WANGARI, E. 2002. Lifespan development revisited: African-centered spirituality throughout the life cycle. Journal of Adult Development, 9(1):71-78.

WOOD, L., IVERY, P., DONOVON, R. \& LAMBIN, E. 2013. To the beat of a different drum: improving the social and mental wellbeing of at-risk young people through drumming. Journal of Public Mental Health,12(2):70-79. 